\title{
O AUDIOVISUAL COMO PRODUTOR DE HISTÓRIAS
}

\section{The audiovisual as a producer of stories}

\author{
Jane Márcia Mazzarino ${ }^{1}$ \\ Rodrigo Müller Marques ${ }^{2}$
}

\begin{abstract}
RESUMO
Na contemporaneidade um leque de dispositivos comunicacionais possibilita modos de se comunicar e de criar documentos históricos. Investiga-se como um produto audiovisual pode ser estratégico para a construção do conhecimento histórico. Trabalhar a História a partir da educomunicação, explorando a produção audiovisual, dinamiza, torna participativo e pluraliza os modos de "fazer História". Realizou-se um estudo qualitativo, com uso de revisão bibliográfica e pesquisa aplicada e intervencionista, na qual se explorou a pesquisa-ação, tendo como resultado a produção de um documentário com alunos da Escola Estadual de Ensino Médio Paverama/RS. A análise dos dados se deu etnograficamente. Através da produção audiovisual se evidenciou o emergir de histórias a partir da História Local. Como resultado se gerou aprendizagem e a construção do saber histórico através da experimentação com audiovisual no contexto escolar.
\end{abstract}

Palavras-chave: História; Educomunicação; Experimentação.

${ }^{1}$ Doutorado em Ciências da Comunicação pela Universidade do Vale do Rio dos Sinos (2005), com estágio doutoramento na Universidade Nova de Lisboa (UNL), mestrado em Ciências da Comunicação pela Universidade do Vale do Rio dos Sinos (2001) e graduação em Comunicação Social com Habilitação em Jornalismo pela Universidade do Vale do Rio dos Sinos (1991). Atualmente é professora titular da Universidade do Vale do Taquari. Atua no Programa de Pós Graduação Ambiente e Desenvolvimento (mestrado e doutorado), e nos cursos de graduação em Comunicação Social.

2 Graduado em História (Univates), mestrando no Programa de Pós-Graduação Mestrado em Ambiente e Desenvolvimento, pesquisador da área da Educomunicação, com trânsito em História, Comunicação, Educação, Patrimônio e também agricultura. 


\begin{abstract}
In the contemporaneity, a range of communication devices enables methods of communication and the creation of historical documents. It is being investigated how an audiovisual product can be placed as strategic to the construction of historical knowledge. To work History starting from the educommunication, exploring an audiovisual production, boost, becomes participative and pluralizes ways of "making history". A qualitative study was carried out, using bibliographic review and applying interventionist research, in which an action-research was explored, resulting in a production of a documentary with students from the Escola Estadual de Ensino Médio Paverama/ RS. An analysis of the data was done ethnographically. Through the audiovisual production it was evident the emerge of histories, starting from Local History. As a result, learning and a construction of historical knowledge were generated through experimentation with audiovisual in the school context.
\end{abstract}

Keywords: History; Educommunication; Experimentation.

\title{
Introdução
}

As novas tecnologias e o espaço escolar estão cada vez mais conectados, expondo novos modos de modos de ver, ler e aprender. O ensino de História se encontra permeado por desafios, entre eles o uso de novas Tecnologias de Informação e Comunicação (TICs). Como a história nos mostra, as tecnologias são meios que influenciaram a trajetória da humanidade, argumento reforçado por Freire et al. (2015), ao afirmar que o ser biológico "segue o mesmo", mas os artifícios e ferramentas usadas é que mudaram. Neste sentido Flusser (2007) ressalta que: a leitura do mundo a partir de audiovisuais e de telas é cada vez mais presente no cotidiano. Deste modo, as TICs produzem mediações, as quais muitas vezes são estruturantes nas relações sociais (políticas, culturais, além de comunicativas).

$\mathrm{O}$ artigo trata da produção de um audiovisual que explorou as mudanças ocorridas no meio rural nas últimas décadas, no município 
de Paverama, localizada no Vale do Taquari, interior do Rio Grande do Sul. Participaram do processo alunos, agricultores, um professor e os pesquisadores. Investiga-se como um produto audiovisual pode se colocar como um lugar/espaço estratégico para a construção do conhecimento histórico ao fazer emergir diferentes histórias.

\section{Método}

Dentre as possibilidades, optamos pelo uso da revisão bibliográfica e estudo de campo, de caráter intervencionista, quando se explorou a pesquisa-ação e o olhar etnográfico (AGROSINO, 2009; ECKERT; ROCHA, 2008; GIL, 2002; VERGARA, 2005).

Na pesquisa qualitativa há a oportunidade de realizar exames cruzados com os dados obtidos, triangular a informação angariada e validar aquelas obtidas pelas diversas fontes, sem perder a flexibilidade (GONZAGA, 2006).

Para a pesquisa bibliográfica (GIL, 2002), realizamos a leitura de periódicos, revistas, livros e artigos científicos relacionados às áreas da Comunicação, Educação e História, selecionando esses materiais através de autores que são referências nesses campos, e em bases de dados (Scielo e Anais dos congressos Intercom e Compós entre 2010-2016).

A pesquisa intervencionista (VERGARA, 2005) se insere num contexto que busca pensar possibilidades para o ensino de história, além de modificar a realidade estudada, tendo em vista que toda ação é uma ação sobre o mundo. No caso desta pesquisa houve o engajamento de alunos que estudam na Escola Estadual de Ensino Médio Paverama ${ }^{3}$ na produção audiovisual.

Os alunos participaram das tomadas de decisão (GIL, 2002). Envolveram-se nas diferentes etapas do audiovisual: roteiro, gravações e edição. Assim, durante toda a pesquisa, a interação entre mediador e o grupo criou rumos que não estavam pré-estabelecidos.

3 Oito alunos do $2^{\circ}$ ano A noturno participaram da produção audiovisual. Outro artigo de mesma autoria explora a prática de produção audiovisual a partir dos princípios educomunicativos. Há uma impossibilidade de pensar esse artigo sem expor que através da construção entre grupo e pesquisadores, nem o audiovisual nem boa parte das análises poderiam ser realizadas. 
Para o registro dos dados se fez uso do diário de campo, anotando as práticas e observações feitas pelo grupo, utilizando-se, para esta etapa, do relato etnográfico.

Pode-se entender que o diário tem um caráter indutivo (acúmulo descritivo de detalhes para construção de modelos), sendo também dialógico e holístico (busca revelar um retrato o mais próximo possível da completude do grupo estudado) (AGROSINO, 2009). O modelo de narrativa a ser empregado nos relatos do diário, conforme o autor, inicia por uma introdução (explica o porquê do estudo), caracterização da cena (descreve a cena de coleta), a análise (descrição com detalhes de padrões socioculturais) e, finalmente, uma conclusão.

Um elemento fundamental do relato etnográfico consiste na observação do grupo estudado (o grupo tem ciência disso), coleta de dados sistemática (através do diário de campo) e análise do diário, além de ter a participação efetiva do pesquisador junto com o grupo (AGROSINO, 2009).

O registro escrito é de suma importância, com suas notas e texto. $\mathrm{O}$ ato de tomar nota, de escrever e descrever define a capacidade de recriar formas culturais que "[...] permitem exercitar a habilidade de lhes dar vida novamente, agora na forma escrita, com base em uma estrutura narrativa." (ECKERT; ROCHA, 2008, p. 8).

$\mathrm{Na}$ análise dos dados coletados, emergiram microcategorias que foram agrupadas em macrocategorias, não se restringindo o estudo a categorias $a$ priori, valorizando-se as categorias emergentes, conforme propõe Moraes (2005). Este método foi utilizado tanto na pesquisa exploratória quanto nas análises aprofundadas, decorrentes do processo de produção audiovisual.

A partir das faces e possibilidades existentes em procedimentos audiovisuais, relacionou-se o ensino de história e a educomunicação, gerando um documentário que se coloca em análise no presente artigo, denominado "Agricultura: do manual ao automático". Ao todo, 12 agricultores foram entrevistados e, assim, se retratou o uso de máquinas na agricultura.

As fontes audiovisuais são vistas como novas e desafiadoras, trazendo tensão entre "[...] subjetividade e objetividade, impressão e testemunho, intervenção estética e registro documental [...]" (NAPOLITANO, 2001, p. 237). Por outro lado se coloca como 
arquivo possível de historicidade e de produção do conhecimento histórico. Esta forma de armazenamento de memória é um documento complexo e multifacetado, que envolve diferentes agentes na confecção do saber histórico, além de ter seu uso estendido para o ensino de história nas salas de aula.

Para a abordagem do objeto de estudo como se propõe, valemo-nos das contribuições da micro-história, que possibilitou pesquisar sobre as mudanças que ocorreram a partir da entrada de máquinas na agricultura em Paverama/RS nas últimas décadas, por meio de aberturas e tessituras em diferentes ramos historiográficos, suscitados a partir da micro-observação, do olhar atento e da tecnologia audiovisual. Assim, o recorte histórico dado no filme produzido com os estudantes reduziu a escala de observação no intuito de enxergar aquilo que escapa à macro-história e lidar com as especificidades relativas ao objetivo dessa pesquisa (BARROS, 2004; LEVI, 2011; 2015).

Para diminuir a ótica de observação, "[...] a micro-história propõe a utilização do microscópio ao invés do telescópio [...]" (BARROS, 2004, p. 154). Segundo Barros (2004), ela não se empenha em explicar o todo social a partir do fragmento, mas cria a possibilidade de "[...] enxergar algo da realidade social que envolve o fragmento humano examinado" (p. 156). Nesse sentido, busca-se no particular para falar do local e para realizar perguntas grandes e gerais, capazes de suscitar infinitas contestações (LEVI, 2015). A micro-história, no entanto, não se esvazia no local, mas usa do microscópio para ver coisas grandes, atenta para nuances, para sujeitos e grupos (enquanto representativos que se retroalimentam) com dinamismos próprios, envoltos em relações pessoais, locais, nacionais e globais (LEVI, 2011; KARSBURG, 2015).

A micro-história parte de um espaço microrrecortado, de uma prática social específica, das trajetórias de atores sociais, núcleos de representação, dentre outros. Pode-se dizer que a "[...] prática microhistoriográfica não deve ser definida propriamente pelo que se vê, mas pelo modo como se vê" (BARROS, 2004, p. 154). Nesta abordagem há tratamento intensivo de fontes e um modo peculiar é utilizado para "ler os indivíduos", a partir do que a interpretação histórica deve ocorrer. Enfim, exercitar a micro-história é tatear a complexidade que engendra conflitos, solidariedades e identidades 
pessoais e grupais (BARROS, 2004; LEVI, 2011; 2015; KARSBURG, 2015).

Ao longo da intervenção por meio da produção de um documentário sobre as máquinas na agricultura em Paverama/RS, utilizamos como pressupostos metodológicos para o ensino de história a história pública e a consciência histórica, os quais buscam aproximar a comunidade do conhecimento acadêmico, produzindo-o em conjunto e também observando a importância da história e sua pertinência na vida prática (ALMEIDA; ROVAI, 2013; ROVAI, 2017; MOREIRA, 2017; FERREIRA, 2013; RÜSEN, 2001; 2006).

\section{Da história pública}

Diante da amplidão do mundo e das alternativas de diálogo da academia com a sociedade, a história pública surge como uma potência ao se colocar como um conjunto de práticas que busca difundir o conhecimento histórico e dar visibilidade à cultura popular através das tecnologias, ampliando assim o leque de possibilidades, tanto do produzir quanto do compartilhar histórias (ALMEIDA; ROVAI, 2013). As TICs abrem espaços profícuos para a história pública, visto que oferecem novas formas, meios e redes de contato, onde os fluxos são constantes e as apropriações diversas. Nessa diversidade é que residem as possibilidades de diálogo entre academia e sociedade.

A história pública se coloca como um caminho de conhecimento e prática, um modo de fazer história por meio da preservação da cultura material e com a colaboração para a reflexão da comunidade sobre si, relacionando passado e presente. Propõe-se, assim, a ampliação do espaço e do público ao conhecimento científico produzido na academia, fazendo ciência histórica por meio de uma ponte de comunicação entre o trabalho acadêmico e a sociedade, sem perder a seriedade e o rigor científico (ALMEIDA; ROVAI, 2013; ROVAI, 2017).

Através da publicitação da história é possível engendrar a arena pública a serviço da cultura, seus conflitos e suas circularidades, assim como lidar com o público e sua diversidade, tanto cultural quanto de consumo midiático. Dessa forma, pode-se 
expandir o saber histórico através do acesso a arquivos, acervos e pessoas (história oral), ao compartilhá-lo com uso das mídias, mediadoras de nossas construções culturais, econômicas e sociopolíticas (MARTÍN-BARBERO, 1997; OROFINO, 2014; ROVAI, 2017).

O cinema-história através de documentários se coloca como inerente ao processo de construção da história pública, fomentando o contato com o passado e suscitando a possibilidade de reconhecimento de processos passados influentes no presente, nos modos de viver e representar o mundo. Dessa forma, comunicar experiências humanas não deve ser apenas entretenimento, mas sim uma forma de diálogo com as demandas sociais, culturais e políticas, com seus tensionamentos e dinâmicas próprias e coletivas. Assim, a história pública auxilia na construção, na democratização da produção de arte e educação e no diálogo entre saberes acadêmicos e a comunidade (ALMEIDA; ROVAI, 2013; FERREIRA, 2013; MOREIRA, 2017; ROVAI, 2017).

Democratizar e fazer arte através da criação de narrativas históricas por meio dos audiovisuais se coloca como possibilidade ampla e profícua. As sensibilidades cinematográficas a partir da vivência com a comunidade possibilitam socializar e aprender com as mudanças do processo histórico, passado e presente, em diversos espaços, meios e com os sujeitos envolvidos no processo (ALMEIDA; ROVAI, 2013; MOREIRA, 2017).

A aproximação e articulação entre história pública e ensino de história possibilita refletir sobre oportunidades de colocar os discentes no centro de sua formação, através da construção de narrativas históricas em um sentido plural, com suas representações e sentidos, em que se fundem a trajetória pessoal, da comunidade e da sociedade a qual ele pertence, com seus referenciais culturais e suas crenças sendo levadas em consideração (MOREIRA, 2017). A partir do audiovisual produzido com os alunos, ocorreram aproximações com a história pública e suas potencialidades, tanto no campo educativo da história quanto no seu ínterim científico. 


\section{Da consciência histórica}

A consciência histórica utilizada como pressuposto metodológico cobre todas as formas de pensamento histórico, através da experiência do passado e de sua interpretação, bem como uso e função da história na vida prática pública e privada. Ela orienta a vida através da estrutura do tempo, de insights que podem ser acoplados aos papéis que o conhecimento histórico estabelece na vida prática. A consciência histórica opera na formação da identidade humana por meio da comunicação entre si com os fluxos temporais passados, presentes e futuros (RÜSEN, 2006).

Para Rüsen (2001), a consciência história, enquanto categoria, agencia a experiência do passado e a interpretação deste pelos sujeitos. Ela é “(...) a realidade a partir da qual se pode entender o que a história é, como ciência, e por que ela é necessária" (RÜSEN, 2001, p. 56). Em suma, refere-se ao conjunto "[...] das operações mentais com as quais os homens interpretam sua experiência da evolução temporal de seu mundo e de si mesmos, de forma tal que possam orientar, intencionalmente, sua vida prática no tempo" (RUSEN, 2001, p. 57). Essa interpretação é inerente ao humano e faz parte do seu constituir-se e de seu atuar no mundo.

Segundo Rüsen $(2001 ; 2006)$, a consciência histórica é o processo fundamental de socialização e individualização humana, colocando-se em situações da vida prática humana (experienciações e interpretações do tempo). A questão básica é como o passado é experienciado e interpretado de modo a se compreender o presente e antecipar o futuro. O aprendizado de história para Rüsen $(2001 ; 2006)$ articula diferentes campos de interesse didático, unidos em uma estrutura coerente. Com o audiovisual há trocas amplas entre didáticas e linguagens "novas e antigas", trazendo em si o potencial de "organização" do tempo enquanto construção e interpretação dos fluxos passados que se encontram presentes no que está e no que virá. A produção audiovisual possibilitou experienciações diversas do tempo (ir a campo, entrevistar, tocar, sentir, observar, etc.).

A consciência histórica permeou a produção audiovisual e suas intenções enquanto material didático para o ensino e pesquisa no campo historiográfico, tensionando temporalidades. A partir dos 
diários de campo, das vivências e das trocas que ocorreram durante a intervenção, os alunos experienciaram, junto com os agricultores, a consciência histórica enquanto atribuição da vida prática, de quem eles são e do panorama temporal que permeia o fazer histórico na e para a vida humana. $\mathrm{O}$ documentário surge como uma composição diversa de um fazer historiográfico a partir do ensino de história.

\section{Da história local}

A História Local recuperada através da história oral por meio da produção audiovisual desvelou nuances da vida cotidiana e desdobramentos, que acompanham pessoas que viveram o passado e que hoje habitam esses espaços (ou espaços similares), localizando-se algumas continuidades e rupturas, tradições que resistem e outras que se refazem ou surgem, elencando traços formativos da sociedade próxima do pesquisador/professor/aluno (FREIRE; JUNIOR; LIMA, 2015).

O estudo de história regional e local nem sempre tiveram grande relevância no mundo acadêmico e escolar. Apenas a partir da década de 1980 que surgem trabalhos mais sistematizados sobre o assunto, graças à já citada História Nova (SILVA, 2013).

A história regional e local aproximam o pesquisador (ou o grupo) de seu "objeto" de estudo. Por tratar de especificidades, deixa brechas férteis para pesquisa e inserção de novos grupos nas narrativas (SILVA, 2013), o caso das visões de mundo dos agricultores.

Segundo Silva (2013), essa história permite ao alunopesquisador refletir sobre o contexto que vive, possibilitando-lhe um olhar atento às mudanças ocorridas ao longo do tempo. Observou-se que grande parte do grupo tinha contato com a agricultura, "[...] o que aproxima o aluno da produção, além de proporcionar ligações entre pesquisadores e entrevistados" (DIÁRIO DE CAMPO, 17/09/2016).

Pode-se notar nas falas dos alunos que ocorreram relações de comparação entre presente e passado, identificando-se dificuldades e facilidades nos períodos, assim como mudanças de espaço-tempo. Em um dos encontros uma aluna comentou que o sistema capitalista cobrava dos agricultores a necessidade de usar tecnologias para 
aumentar a produção, o que havia sido ressaltado por uma entrevistada, quando atribuiu à tecnologia o papel de "mal necessário".

Realizar o estudo comparativo entre micro e macro história, criando ambientes de reflexão tanto por parte do grupo quanto do pesquisador, fez com que aflorassem relações entre realidade vivida e conteúdos escolares, que ajudaram a enriquecer o debate com o ingrediente da criticidade.

O objetivo do audiovisual não era estudar em específico a história de Paverama ${ }^{4}$, embora perpassasse a formação do município. Paverama foi colonizada principalmente por descendentes de açorianos e de alemães. É um município novo, de característica rural (com poucas empresas e um centro urbano um tanto pequeno), além de apresentar aspectos culturais e sociais marcantes (DUPONT, 2012).

Durante o diálogo entre pesquisador e grupo, trabalharam-se questões relacionadas à descendência dos membros do grupo. Observou-se que havia descendentes de portugueses, italianos, alemães e indígenas dentre eles e, a partir daí, foi possível demonstrar como Paverama, Rio Grande do Sul e o próprio Brasil foram se constituindo (DIÁRIO DE CAMPO, 21/09/2016).

Com a transversalidade do tema abordado no audiovisual, relações que não se buscavam, emergiram e fizeram o grupo tecer conhecimentos históricos que transcenderam o previsto, adentrando as diferenças culturais e sociais, constituintes da história do município. Assim, abordou-se por exemplo, a existência de Centro de Tradições Gaúchas (CTG) em alguns pontos do município, os bailes de Kerb, em outros, os diferentes sotaques, e as religiões distintas (evangélicos, católicos, ateus, etc.). Todos elementos que constituem arranjos híbridos no território paveramense.

4 A história de Paverama (limitação territorial usada para a produção audiovisual) é vinculada diretamente a Taquari (município mãe). Em 20/12/1987 ocorreu o plebiscito para emancipação política que resultou no desmembramento de ambos, decretado pela Lei no 8.560. Em 13 de abril de 1988, Paverama se emancipa oficialmente (DUPONT, 2012). 
As ligações e construções feitas pelos alunos e pelo pesquisador surgiram de leituras, experiências e, principalmente, das entrevistas, ou seja, das fontes orais, as principais do audiovisual, o que possibilitou a rememoração e, com isso, registrar características históricas de determinado território em dado período.

\section{Da história oral}

A partir da década de 1980, a História Oral ganha prestígio e uso, tanto na pesquisa quanto no ensino, passando gradualmente a ser utilizada como "ferramenta" nesses processos. O uso de História Oral na educação permite captar elementos que não estão documentados em evidências tradicionais (NÓBREGA; SENNA; SOLDERA, 2009), gerando possibilidades de complexificar, cruzar dados e buscar outros "olhares e tatos" sobre a história, rememorando de modo humano o passado, em sua inexatidão e possibilidade de construção.

A intenção não era realizar uma pesquisa metodológica aprofundada "em História Oral", mas sim utilizá-la como suporte para criar conhecimento histórico, através da produção audiovisual. No documentário, a fala assume importância, através das memórias, tanto individuais como coletivas, por meio das quais construiu-se o contexto de um período histórico específico (primeira metade do século XX até os "dias atuais"). O saber histórico assim construído, a partir da participação dos alunos, enriqueceu o ensino de História, potencializando o método da História Oral, evidenciando a potencialidade dessa metodologia.

Nóbrega et al. (2009) expõe que ao utilizar a História Oral no ensino se possibilita ao aluno o desenvolvimento da habilidade de questionar. $\mathrm{O}$ aluno que pergunta com maior ou menor curiosidade, dialoga com o indivíduo e sua(s) história(s), tornando-se sujeito ativo no fazer histórico. É nesse fazer que o indivíduo pode vislumbrar cores, sabores e exercitar a imaginação, para além da linha escrita. Pode visitar, através da memória individual e coletiva, o passado, mesmo que de um modo particular e subjetivo. Escutar outra pessoa falar sobre sua história é um exercício que gera novos olhares para o outro e para si mesmo. 
$\mathrm{O}$ ato de entrevistar também gera empoderamento do entrevistado, que muitas vezes, têm poucas oportunidades de expor sobre "seu mundo" e seus conhecimentos. Fala é poder (MONTENEGRO, 2003). Alguns até pensam que sabem pouco, mas as entrevistas provaram o contrário. A escuta do outro empoderou por meio do ato de entrevistar. Os alunos tiveram oportunidade de escutar e conhecer diferentes realidade, revendo preconceitos.

Os participantes do processo relataram que perceberam os agricultores de outra forma, como sujeitos repletos de história e se surpreenderam por encontrar agricultores-pesquisadores, que estudam sobre modos de produção mais harmônicos com a natureza (caso de um morador que possui uma Área de Preservação Permanente). Outro agricultor explicou sobre como a máquina afeta os modos de plantio, contou que acessa o youtube e assina revistas sobre agricultura para através delas desenvolver a produção sem gerar estresse para o gado. Essa informação causou surpresa nos alunos.

Os agricultores demonstraram descontentamento com o trato dado às suas demandas e a sua profissão, reclamando da desvalorização e da pouca atenção "do governo" às suas necessidades. Embora não utilizadas como eixo central no audiovisual, estas falas se refletiram em um exercício de escuta e de compartilhamento de voz deste grupo social que, muitas vezes, se encontra marginalizado ou "estereotipado" socialmente.

Foram selecionados momentos, conjunturas e modos de viver, para explicar o que "passou" e o que permanece. Eis uma das especificidades da História Oral, trabalhada com o grupo e importante de destacar: a memória é volátil, descontínua e subjetiva em essência. Não há certo ou errado com exatidão, existindo um emaranhado que, ao ser "desenrolado" e agrupado capacita a "reconstrução" de um determinado contexto. ${ }^{5}$ Assim se evidenciou no audiovisual que a história narrada pelos entrevistados operou através de descontinuidades. Como coloca Caldas

5 Reconstrução no sentido do reconstruir, refundar, revisitar através da memória. Se constrói através dos restos materiais e imateriais, que saltam a partir da fala e ganham consistência no agrupamento. 
Aquilo que entendemos como passado está sempre, inteiro, fragmentado, esgarçado, inexistente, recriado, distorcido, lúcido, múltiplo e vivo naquilo que sentimos e vivemos como presente. Nossa vida pessoal, nossa interioridade, não se recorta em um antes ou um depois ontológico, mas num amálgama viva, ficcional, no qual aquilo que entendemos como antes está inteiro naquilo que sou eu, naquilo que me identifica e me diferencia, num processo criativo intermitente, múltiplo e espesso, conceito ao mesmo tempo de mim, do presente e do passado [...] (CALDAS, 1999, p. 56).

$\mathrm{Na}$ entrevista oral, assim como nos documentos pessoais há tom da experiência, do sujeito, deste modo, “[...] sua narrativa acaba colorindo o passado com um valor [...]" (ALBERTI, 2004, p. 14). Essa "coloração" ajuda a entender um pouco do universo habitado no passado e como o entrevistado se remete a ele.

Um dos alunos comentou durante um dos encontros que ele sentiu a emoção dos agricultores ao falarem do passado, principalmente, pela saudade que sentiam desse tempo que "passou". Saborear a recordação traz um pouco disso, sentimentos sobre o que já não é, afinal, somos seres sociais, culturais e históricos, acompanhados pelas vivências e saberes acumulados e construídos. Sapiens com sapiências ora escondidas, ora escancaradas. Às vezes, só precisamos bater na porta e fazer uma visita ao que passou, e que ainda existe.

Por meio da produção audiovisual ocorreu um aprendizado que levou em conta o outro (FREIRE, 2015; MONTENEGRO, 2003), demonstrando que embora a história tente ainda ser muito objetiva, não é possível descartar o fato de que quem fala, fala de um lugar, construído com as suas vivências e os significados que dá a elas.

Le Goff (2003) atenta para o fato de que a memória humana é maleável e volátil, o que não pode ser ignorado ao se realizar pesquisas que usam a oralidade como principal referência. Assim, trabalhar com os alunos o "esquecimento", as "distorções" e os "enganos" que a memória pode fornecer a quem fala e a quem escuta é necessário, para não se cometer o equívoco de pensar que a história é estática ou "pronta". 
Em história oral, o texto se coloca em movimento. Não cabe expurgar as contradições ou buscar "pureza" e linearidade nas falas. Isso excluiria as fissuras e significações específicas dadas aos fatos. É preciso atentar para a volatilidade da memória e sua construção (LE GOFF, 2003; CALDAS, 1999). Daí a importância de se desenvolver a sensibilidade para interpretar os acontecimentos em sua complexidade.

Caldas (1999), ao escrever sobre oralidade, expõe que ver é codificar e decodificar. É maneira de criar e reconhecer conexões e mediações entre instâncias ônticas. Olhar é então, instaurar paralelos, identificar nosso "cheiro", é "apalpar" o conhecimento e se surpreender (ou se espantar) com o outro, podendo, assim, vê-lo como outro. Olhar é '[...] 'degustar', com horror ou prazer, alteridades; é vivenciar como a única realidade, ou a realidade privilegiada, o real criado pelo social." (CALDAS, 1999, p.28).

O documentário fez todos apalparem e se espantarem a partir do diálogo e da reflexão, como coloca Caldas (1999). A criação emergiu da dialogicidade envolvida na entrevista, permeada de falas e silêncios, imagens, memórias e desejos. Informações, dados e recordações geraram aprendizados de uma história que não está documentada oficialmente, relativa àqueles que constroem, por meio de suas práticas, o cotidiano.

$\mathrm{O}$ que se conseguiu com as entrevistas e a gravação do documentário foi a "comunicabilidade da experiência", a criação do conhecimento de modo a se "[...] compreender a realidade por meio de novas maneiras de reflexão [...]" (CALDAS, 1999, p. 75), ainda pouco exploradas: por meio do compartilhamento dos saberes através de um documentário. Usou-se da experiência para criar algo novo. Algo que estava lá, mas que através de trabalho conjunto (grupo, pesquisador e entrevistados) veio à tona, emergiu e mostrou que a história é feita do presente, de saberes populares, de reflexões acadêmicas e, não em menor importância, de emoção.

\section{Da história ambiental}

Também o campo da história evolui com o tempo. Como Bourdé e Martin (2012) colocam em seu texto sobre as escolas 
históricas, a Escola dos Annales inaugura uma grande abertura do campo da História. Temas que eram pouco tratados e/ou metodologias novas rompem com "paradigmas" e hibridizam o modo de escrever e fazer História.

A História Ambiental aparece ao dialogar com as ciências naturais e situar-se "[...] em um contexto teórico muito diferente daquele que alimentou as formulações deterministas do passado" (PÁDUA, 2010, p.90). Com ele o campo da história se complexifica, evita reducionismos (geográficos, biológicos, etc.) e abarca em si potencialidades de outras ciências, criando pontos de ligação e de retroalimentação que complexificam o relacionamento entre sociedade e natureza, com seus desdobramentos presentes, passados e futuros.

Segundo Pádua (2010) e Martínez (2011), a história ambiental problematiza e explora as interações entre sociedade e natureza, focando nas ocupações humanas, organizações produtivas, políticas públicas e as práticas culturais dos diferentes grupos com suas dinâmicas socioeconômicas, além de ser uma prática de cidadania. As entrevistas e os diálogos fizeram emergir aspectos sociais, tecnológicos, geográficos e culturais, e, a partir delas, "apareceram traços" da História Ambiental. Buscou-se, como coloca Pádua (2010), incluir práticas e estudos das relações entre sistemas naturais (e suas historicidades) e as sociedades humanas (com suas experiências vividas), possibilitando a ligação acadêmica entre o homem e o meio ambiente de forma mais clara e coesa.

Ao longo do tempo, a História e seu ensino incorporaram ideias, processos sociais e conceitos que são redimensionados e redefinidos, por terem interface com os temas de sustentabilidade, biodiversidade, patrimônio e diversidade cultural, entre outros, demonstrando assim uma preocupação latente e ampliada com a questão ambiental (MARTÍNEZ, 2011).

Morin (2003) escreve sobre a importância da interdisciplinariedade e dos riscos ocasionados pelos reducionismos que acompanham o ensino separado em seus "nichos e disciplinas", não auxiliando para a construção de um olhar mais global e complexo. A preocupação com a questão ambiental, que surge com os novos movimentos sociais, aponta a necessidade de uma educação cada vez mais humana, formadora e transformadora também para o 
campo da História Ambiental. Daí a importância de se ter o envolvimento de alunos com a pesquisa nesta área, gerando-se conhecimento sobre as relações produtivas e de convívio entre sociedade e meio ambiente, as quais determinam processos históricos, sociais e culturais.

Por ser um país megadiverso, com grande extensão, variedade de contrastes e de ecossistemas, além de ter uma rica diversidade regional e cultural, o Brasil é um cenário profícuo para estudos ambientais. Soma-se a isso explorações que estão por vir, como o "pré-sal", o uso de biocombustíveis e outras ações com miradas econômicas, mas que influenciam diretamente no meio ambiente e criam outras dinâmicas entre sociedades e sistemas naturais (MARTÍNEZ, 2011; PÁDUA, 2010). Cria-se assim um campo vasto e importante de atuação para a História Ambiental, que vai além do academicismo puro, podendo adentrar o tecido social em seus meandros.

O vídeo aprofundou justamente a observação do relacionamento entre homem e sistemas naturais, com as mudanças ocorridas entre eles devido ao mercado e suas "leis", que determinaram mudanças de cultivos e de modos de produção. Assim, o documentário explorou a história local ambiental por meio da história oral, abrindo possibilidades inventivas para o ensino neste campo, em sua interface com a educação ambiental, tema transversal na Educação Básica.

\section{Composições emergentes}

A diversificação de fontes e oportunidades de pesquisa que possuímos hoje, a entrevista, a visitação a lugares com cultura material histórica, as vivências e as tecnologias enriquecem e deixam o campo da história profícuo, multifacetado e mais abrangente. A pesquisa que culminou no audiovisual explorou o cotidiano, a produção agrícola, a história coletiva, mostrando uma história "vista de baixo", com protagonismo de cidadãos tidos como "comuns", em um território próprio, influenciado pelo contexto social, político, econômico e ambiental. Essas características possibilitaram, para os 
participantes (grupo de alunos, agricultores e pesquisadores), aproximarem-se de processos construtivos da consciência histórica.

Nas reuniões com o grupo de alunos se trabalharam estas questões e também as relações do passado com o presente, buscando aproximações através do diálogo entre a produção em décadas anteriores e atualmente, caracterizando-se as mudanças políticas de cada período (observando, por exemplo, que para eles a ditadura não gerou o mesmo impacto que em centros urbanos), os modos de viver a infầncia, questões de qualidade de vida, festividades, enfim o cotidiano dos entrevistados.

$\mathrm{Na}$ perspectiva de um mundo globalizado, interligado e complexo, que envolve ecossistemas comunicativos, sociais e ambientais (CASTELLS, 2006; MORIN, 2000; 2005, SOARES, 2011) foi instigante pesquisar a relação do homem com a terra, seus modos de produção, de plantio e as mudanças que tiveram de encarar devido às condições e exigências do mercado, à necessidade de ganhos na qualidade de vida e aos custos para comprar e manter as tecnologias de produção.

As linhas teóricas usadas para o documentário possibilitaram o diálogo sobre os modos de fazer e escrever história, trazendo o aluno para o debate e inserindo as fontes históricas e as correntes historiográficas no ensino. Sabe-se da impossibilidade de tratar décadas em apenas um vídeo de pouco mais de 20 minutos, ou com algumas entrevistas apenas, mas, tendo em vista as restrições de tempo e as condições materiais, foram exercitdas possibilidades de se estudar a história local, nacional e global, através de aproximações.

Por meio do documentário, abordou-se com os alunos que o Brasil, principalmente após a década de 1950, entra em um período de busca pela modernização que levou grande parte da população para as cidades. Como coloca Fausto (2002), na década de 50 se ampliaram as oportunidades de emprego no setor industrial, especialmente, no setor de serviços. Além disso, o autor expõe que de outro lado, havia uma tendência a mudança de atividades rurais que, "[...] com menor absorção de mão-de-obra, empurraram a população rural do campo para as cidades" (p. 295). Nesse período o Brasil ainda podia ser considerado um país predominantemente "rural". A saída do campo para a cidade ainda ocorre, quando por exemplo, alguns entrevistados 
relatam que os filhos não ficam na área rural e acabam buscando trabalho na cidade.

Como entrevistamos moradores de diferentes localidades de Paverama (Linha Brasil, Linha Santana, Morro Bonito, Cabriúva, Bom Jardim, Boa Esperança, "Cidade Baixa" e Santa Manoela), pôde-se notar principalmente descendentes de portugueses e alemães (dois processos migratórios que marcaram a história do município). A partir disso, trabalhou-se com o grupo de alunos essa característica, de uma formação que carrega consigo traços diversos e desse modo, problematizaram-se as fronteiras e a ocupação do espaço.

Trata-se de uma Paverama que "descende" de Taquari e que, assim como sua "cidade-mãe", se vê ocupada inicialmente por descendentes de açorianos que tem por intuito ocupar o território e inibir/dificultar o avanço dos espanhóis. De outro lado, é formada também por imigrantes alemães, que posteriormente buscavam novas oportunidades, pois, como coloca Schwarcz e Starling (2015, p.33) a Europa, no final do século XIX e início do século XX "[...] expelia sua população pobre e seus pequenos proprietários endividados [...]". Vale ressaltar, como coloca Dupont (2012) que as populações indígenas também estiveram presentes no território paveramense, ajudando a formar o mosaico cultural e social da cidade.

Segundo Schwarcz e Starling (2015), a região Sul do país se encontrava com grandes áreas não ocupadas e a partir disso se instalou um modelo de imigração baseada em pequenas propriedades, que se encontravam muito isoladas. Esses imigrantes estavam sujeitos "[...] a todo tipo de adversidade: ataques indígenas, maus-tratos por parte da população local, dificuldades de comércio." (SCHWARCZ; STARLING, p. 323). Portanto, as possibilidades de temas da História que podem ser trabalhados por meio do audiovisual a partir do tema definido pelos alunos foram múltiplas.

Foi possível, através dos "links" abertos pelas entrevistas e pela produção audiovisual debater, mesmo que de modo breve, sobre imigração, dificuldades de colocação, agricultura de subsistência e desenvolvimento de localidades e do comércio, além de abordar as relações sociais.

Com o documentário se confirmou a mudança de realidade a partir do uso de máquinas no campo, que alteraram drasticamente o cenário e exigiram uma maior produtividade. Como Fausto (2002) 
escreve, houve uma "[...] racionalização das atividades agrícolas, buscando-se maior produtividade e maior lucro [...]" (FAUSTO, 2002, p. 298). O autor afirma que, a partir dos anos de 1950 a produção agrícola no Brasil deixa de se centrar no café e passa a ter muita importância a soja e as pastagens (para pecuária), práticas ainda atuais. As falas dos entrevistados confluem com tais afirmações ao exporem que, "antigamente", houve uma época de plantio de soja, realizado a mão, onde a paisagem, em algumas localidades, se resumia a esse cultivo, demonstrando certa "sobreposição de cultivos".

O documentário insere também as máquinas em um período mais recente, "pós 2000", na agricultura de pequeno porte. Se levarmos em conta abertura de crédito para a agricultura familiar que ocorreu nos últimos anos e a facilidade em se obter máquinas para produção agrícola, percebe-se uma agricultura familiar que se "moderniza" somente "agora", ao passo que o latifúndio, de modo geral, com a chamada Revolução Verde já havia passado por essa etapa em meados da década de 1970. A Revolução Verde expõe o modo de produção a partir de grande escala, através de latifúndios e do uso de máquinas e de agrotóxicos. A implementação de tecnologia na produção agrária se deve à "necessidade de produzir mais e mais". A lógica de produzir para vender em larga escala impacta os modos de vida e de trabalho dos agricultores de Paverama. O investimento em tecnologias para aumentar a produção, segundo eles, aumenta o tempo de trabalho, mas não é vista com "maus olhos", até porque ao se produzir mais para alimentar o sistema vigente, adaptando-se à necessidade de mercado e buscando produzir em larga escala para venda, há retorno financeiro.

A história necessita de conexões para fazer sentido aos alunos. Conhecimentos isolados e que não se aproximam das realidades vividas e vistas fazem do campo histórico algo sem significado para quem o estuda. A proximidade auxilia a compreensão do que se expõe e com a produção audiovisual, ligaramse conhecimentos acadêmicos e populares.

As entrevistas reforçaram o que as autoras Schwarcz e Starling (2015) pontuam: a agricultura arcaica demonstrava que apesar dos investimentos em industrialização pelos quais o país passou, principalmente após 1950, algumas regiões não foram 
atingidas. Como o enfoque era e ainda é a monocultura voltada para exportação, deixa-se a agricultura familiar, muitas vezes em segundo plano.

As falas dos agricultores no documentário confluem com o pensamento de Fausto

[...] Em 1975, cerca de 3,64 milhões de estabelecimentos agrícolas, ou $73 \%$ do total, cultivavam a terra sem uso do arado, fosse ele mecânico ou de tração animal. A mesma proporção de famílias rurais (73\%) tinha uma renda monetária per capita da metade do salário mínimo, ou menos, em 1980 (2002, p. 299).

A fala de Orlando ${ }^{6}$ no documentário, expõe que um "colono antigamente" ganhava pouco e com uma "vaquinha de leite podia tirar algo próximo de um salário mínimo". Segundo as entrevistas, é nos últimos anos que o uso de máquinas se torna comum, modernizando-se a produção agrícola e dando novos ares e cores ao campo (fumaça e óleo diesel também). Hoje os usos de máquinas têm espaço desde o plantio até a colheita ou processamento da produção (tratores, implementos, ordenhas, tanques de armazenamento, etc.).

\section{Considerações finais}

O professor de história parte de seu conhecimento para ensinar sua disciplina. $\mathrm{O}$ aluno também parte de seus conhecimentos próprios para buscar a aprendizagem. A estratégia de criar um processo de educomunicação, explorando-se a linguagem audiovisual constitui um elo entre educação e comunicação, entre ensino e pesquisa em História, criando significações por meio da participação, valorização e diálogo dos saberes de todos envolvidos no processo.

A educação cada vez demonstra mais sua necessidade de se aproximar do que ocorre fora dos muros da escola. Apropriar-se, experimentar, produzir, conhecer e compartilhar por meio de produção participativa de conhecimento histórico e do ensino da disciplina é um caminho inovador.

6 Outro entrevistado no audiovisual. 
A prática educomunicativa se encaixa bem em atividades que podem ser realizadas no cotidiano escolar e que tem a potência de auxiliar muito nos processos de ensino/aprendizagem. O saber sem comunicação, sem troca e sem diálogo se torna estanque, isolado, não passa de informação.

Dar vivacidade à História por meio de um documentário que criou diálogos, pluralizando, complexificando e embelezando (como produção artística) a produção científica demonstrou a potencialidade de apropriação popular das tecnologias de informação e comunicação (TICs).

Mais que isso, a experiência de intervenção educomunicativa aliada ao ensino de História constituiu uma mandala de saberes neste campo de conhecimento composta por uma amarração inusitada entre notas da micro-história, da história pública, da consciência histórica, da história local, da história ambiental e da história oral. Foi no fazer livre que ela surgiu.

Assim, a produção do audiovisual mostrou que diferentes áreas da História se interligam. E que as possibilidades abertas e exploradas de valorização de saberes populares na pesquisa-ação, junto com o conhecimento teórico e acadêmico, possibilitam o trânsito em nichos e entre nichos de modo a produzir conhecimento através da cooperação entre diferentes saberes.

\section{Referências bibliográficas}

AGROSINO, Michael. Etnografia e observação participante. Porto Alegre: Artmed, 2009.

ALBERTI, Verena. Ouvir contar: textos em história oral. Rio de janeiro: FGV, 2004.

ALMEIDA, Juniele Rabêlo de; ROVAI, Marta Gouveia de Oliveira. História pública: entre as "políticas públicas" e os "públicos da história". In: XXVIII SIMPÓSIO NACIONAL DE HISTÓRIA (ANPUH): CONHECIMENTO HISTÓRICO E DIÁLOGO SOCIAL. Anais. 2013, Natal/RN. p. 1 - 15. Disponível em: $<$ http://snh2013.anpuh.org/resources/anais/27/1364156201_ARQUIV 
O_TextoFinal_ANPUHNATAL_HistoriaPublica_2013.pdf $>$. Acesso em 16 jul. 2018.

BARROS, José D'Assunção. Abordagens. In:__ O campo da História: especialidades e abordagens. Petrópolis, RJ: Vozes, 2004. BOURDÉ, Guy, MARTIN, Hervé. As escolas Históricas. Portugal: Publicações Europa-América, 2012.

CALDAS, Alberto Lins. Oralidade, texto e história: para ler a história oral. São Paulo: Edições Loyola, 1999.

CASTELLS, Manuel. Inovação, Liberdade e poder na Era da Informação. In: MORAES, Dênis de (Org.). Sociedade Midiatizada. 1. ed. Rio de Janeiro: Mauad, 2006.

DIÁRIO de campo 7 de 17/09/2016. Encontro realizado na biblioteca da Escola Estadual de Ensino Médio Paverama (EEEMPA). Paverama. 2016. 3p.

DIÁRIO de campo 8 de 21/09/2016. Encontro realizado na biblioteca da Escola Estadual de Ensino Médio Paverama (EEEMPA). Paverama. 2016. 2p.

DUPONT, Maria Tereza Jantsch. Paverama: ontem e hoje. Porto Alegre: Evangraf, 2012.

ECKERT, Cornelia; ROCHA, Ana Luiza Carvalho. Etnografia: saberes e práticas. Iluminuras. Porto Alegre: n. 21, 2008, 23 p.

FAUSTO, Boris. História Concisa do Brasil. São Paulo: Editora da Universidade de São Paulo, 2002.

FERREIRA, Rodrigo de Almeida. O Filme e a História Pública: diálogos para a educação não-escolar a partir de Chico Rei (1985). In: XXVIII SIMPÓSIO NACIONAL DE HISTÓRIA (ANPUH): conhecimento histórico e diálogo social. Anais. 2013, p. 1 - 15. Disponível em: http://www.snh2013.anpuh.org/resources/anais/27/1364744861_ARQ UIVO_ANPHU13-OFilmeeaHistoriaPublica.pdf $>$. Acesso em: 16 jul. 2018.

FLUSSER, Vilém. $O$ mundo codificado: por uma filosofia do design e da comunicação. São Paulo: Cosac Naify, 2007. 
FREIRE, Paulo. Pedagogia da autonomia: saberes necessários à prática educativa. São Paulo: Paz e Terra, 2015.

FREIRE, Vitoria C. C.; JUNIOR, Antônio G. M.; LIMA, Jeimes M. C. Ensinando História no Brasil: Trajetórias de percursos. In: MAGALHÃES, Antônio Germano; ARAÚJO, Fátima M. L. (Orgs.) Ensino \& linguagens de história. Fortaleza: EdUECE, 2015, p. 17 61.

GASKELL, George. Entrevistas individuais e grupais. In: BAUER, Martin W.; (Orgs.). Pesquisa qualitativa com texto, imagem e som - um manual prático. Petrópolis: Vozes, 2002, p. 64 - 73. GIL, Antônio Carlos. Como elaborar projetos de pesquisa. São Paulo: Atlas, 2002.

GONZAGA, Amarildo Menezes. A pesquisa em educação: um desenho metodológico centrado na abordagem qualitativa. In: PIMENTA, S. G.; GHEDIN, E.; FRANCO, M. A. S. (Orgs.). Pesquisa em educação. São Paulo: Ed. Loyola, 2006, p. 64 - 92.

KARSBURG, Alexandre de Oliveira. A micro-história e o método da microanálise na construção de trajetórias. In: VENDRAME, Maria Ines et al. (Orgs.). Micro-história, trajetórias e imigração. São Leopoldo: Oikos, 2015. p. $32-52$.

LE GOFF, Jacques. História e Memória. Campinas, SP: Editora da Unicamp, 2003.

LEVI, Giovanni. Micro-História e história da imigração. In: VENDRAME, Maria Ines et al. (Orgs.). Micro-história, trajetórias e imigração. São Leopoldo: Oikos, 2015. p. 246 - 262.

. Sobre a micro-história. In: BURKE, Peter (Org.). A escrita da História: novas perspectivas. São Paulo: Editora Unesp, 2011. MARTIN-BARBERO, Jesus. Dos meios às mediações: Comunicação, cultura e hegemonia. Rio de Janeiro: UFRJ, 1997. MOREIRA, Igor Lemos. Sobre História Pública e ensino de história: algumas considerações. Sorocaba: EBR - Educação Básica Revista, v. 3, n. 2, p. $81 \quad$ - 96, 2017. Disponível em: 
$<$ http://www.laplageemrevista.ufscar.br/index.php/REB/article/view/ 233/550>. Acesso em: 16 jul. 2017.

OROFINO, Maria Isabel Rodrigues. Crianças em contextos: novos aportes para o debate sobre infâncias, comunicação e culturas do consumo. In: ROCHA, Rose de Melo; OROFINO, Maria Isabel Rodrigues. Comunicação, consumo e ação reflexiva. Porto Alegre: Sulina, 2014.

MARTÍNEZ, Paulo Henrique. História Ambiental: um olhar prospectivo. Uberlândia: Cad. Pesq. Cdhis, v. 24, n. 1, p. 23 - 36, jan./jun. 2011.

MONTENEGRO, Antonio Torres. História oral e memória: a cultura popular revisitada. São Paulo: Contexto, 2003.

MORAES, Roque. Mergulhos discursivos: análise textual qualitativa entendida como processo integrado de aprender, comunicar e interferir em discursos. In: FREITAS, José Vicente de; GALIAZZI, Maria do Carmo (Orgs.). Metodologias Emergentes de Pesquisa em Educação Ambiental. Ijuí: Unijuí, 2005. p.86-114.

MORIN, Edgar. A cabeça bem-feita: repensar a reforma, reformar o pensamento. Rio de Janeiro: Bertrand Brasil, 2003.

. Introdução ao pensamento complexo. Porto Alegre: Ed. Sulina, 2005.

. Os sete saberes necessários à educação do futuro. São Paulo: Cortez, 2000.

NAPOLITANO, Marcos. A História depois do papel. In: PINSKY, Carla Bassanezi (Org.). Fontes Históricas. São Paulo: Contexto, 2011. p. 235-248.

NÓBREGA, Felipe; SENNA, Adriane; SOLDERA, Lisiane. A História Oral como prática no Ensino de História. Santa Cruz do Sul: Ágora, v. 15, n. 1, p. 126-136, jan./jun. 2009.

PÁDUA, José Augusto. As bases teóricas da história ambiental. São Paulo: Estudos Avançados, v. 24, n. 68, p. 81- 101, 2010.

ROVAI, Marta Gouveia de Oliveira. HISTÓRIA PÚBLICA: a comunicação e a educação histórica. Palmas: Revista Observatório, v. 
3, n. 2, p. 41-65, 2017. Disponível em:

$<$ https://sistemas.uft.edu.br/periodicos/index.php/observatorio/article/. ../3465/9604/ >. Acesso em: 16 jul. 2018.

RÜSEN, Jörn. Pragmática - A constituição do pensamento histórico na vida prática. In: . Razão histórica: teoria da história: fundamentos da ciência histórica. Brasília: Editora Universidade de Brasília, 2001.

. Didática da história: passado, presente e perspectivas a partir do caso alemão. Ponta Grossa/PR: Práxis educativa, v. 1, n. 2, p. 07 16, 2006.

SCHWARCZ, Lilia Moritz; STARLING, Heloisa Murgel. Brasil: Uma biografia. São Paulo: Companhia das letras, 2015.

SILVA, Luís Carlos Borges da. A importância do estudo de história regional e local na educação básica. Natal: XXVII SIMPÓSIO NACIONAL DE HISTÓRIA: CONHECIMENTO HISTÓRICO E DIÁlOGO SOCIAL. Anais. 2013, p. 1 - 11. Disponível em: < http://www.snh2013.anpuh.org/resources/anais/27/1372277415_ARQ UIVO_Artigo-HistoriaRegional_NATAL_pdf $>$. Acesso em: 20 jul. 2017.

SOARES, Ismar de Oliveira. Educomunicação: um campo de mediações. In: CITELLI, Adilson Odair; COSTA, Maria Cristina Castilho. Educomunicação: construindo uma nova área de conhecimento. São Paulo: Paulinas, 2011. p. 15 - 31 .

VERGARA, Sylvia C. Projetos e relatórios de pesquisa em administração. São Paulo: Atlas, 2005.

RECEBIDO EM 30/07/2017 APROVADO EM 07/08/2018 